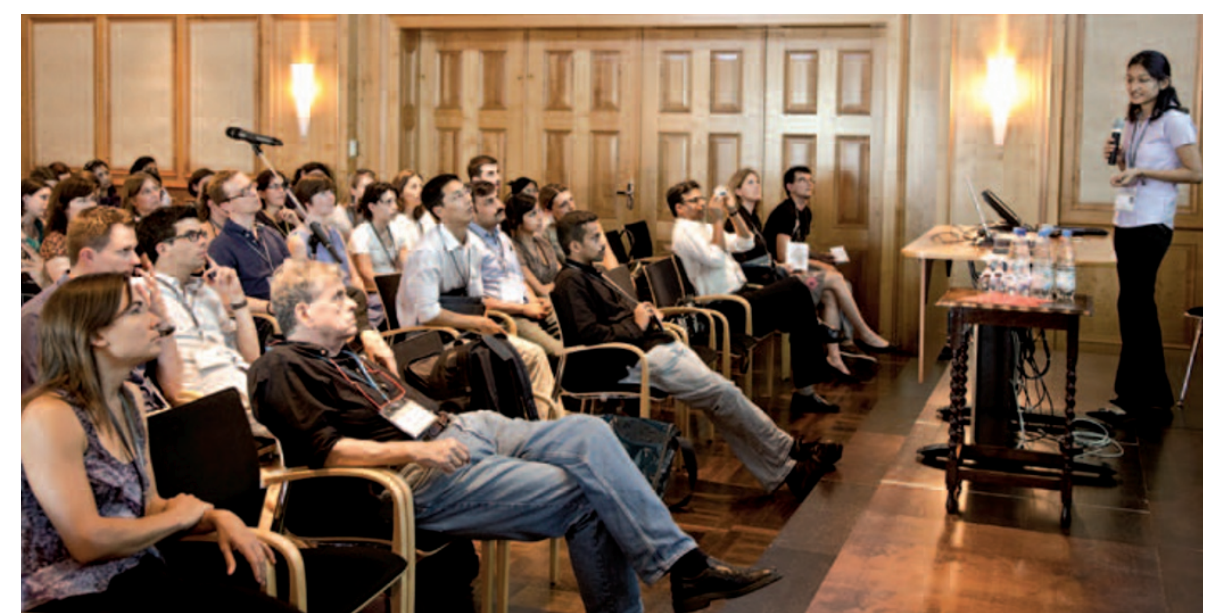

Ciechanover and young researchers listen to Geeta Negi present her work on diabetes neuropathy.

\title{
MASTERCLASS
}

\section{The gathering brainstorm}

\section{In Lindau, a colloquy between a Nobel laureate and three students encouraged the young researchers to grapple with some of the biggest challenges in drug development.}

\section{BY KAT MCGOWAN}

$\mathrm{I}$ twas the stuff of dreams for a young researcher - a chance to be coached by a science superstar. The 'masterclass' that took place on the second day of the 2011 Lindau Meeting of Nobel Laureates was an experiment in which student science took centre stage. Three young investigators gave poster-talk style presentations of their current work to a Nobel prizewinner. The master, in this case biochemist Aaron Ciechanover (see page S4), critiqued each talk. The tone was set early: "Unlike many lectures here that ask about career development," he proclaimed, "this is going to be about science."

Ciechanover, a biochemist at Technion, the Israeli Institute of Technology in Haifa, shared the 2004 Nobel Prize in Chemistry for the discovery of the ubiquitin-proteasome system, the tightly regulated process by which cells tag and dismantle unwanted proteins. This protein quality-control mechanism is crucial to such basic biological phenomena as cell division and DNA repair, and likely to play an essential role in diseases ranging from Alzheimer's, in which proteins aggregate, to cystic fibrosis, in which they are dismantled too quickly.

The three students he chose for the session all explored an aspect of protein folding or processing. But the session soon evolved into a fast-paced lesson on the importance of thinking about how to stop diseases, rather than merely understanding them. Ciechanover's take-home message: responding to today's global epidemics requires the ability to convert scientific ideas into treatments that work.

\section{SURFACING PROBLEMS}

The young researchers' talks focused on three major global health issues: Parkinson's disease, diabetes and tuberculosis (TB). Ciechanover contended that they are all modern diseases. Parkinson's disease, a neurological disorder caused by the loss of dopamine-producing neurons, is rare in people younger than 50 years of age. Until the past 100 years, few people lived long enough to develop it. The rapid global ascent of diabetes can be attributed, at least in part, to affluence: eating foods high in fat and sugar, with a sedentary lifestyle. And the trajectory of TB reveals both the power and the weakness of drug development: beaten into submission by powerful antibiotics in the mid-twentieth century, this infectious disease came roaring back in a menacing new drug-resistant form at the end of the millennium - a nasty reminder that medical triumphs can be short-lived.

First to present was doctoral student Lena Burbulla of the Hertie Institute for Clinical Brain Research in Tübingen, Germany. Burbulla described how the quality control of mortalin, a mitochondrial chaperone protein, goes awry in Parkinson's disease. Normally, explained Burbulla, mortalin assists in refolding misfolded proteins and protecting neurons from protein aggregation, oxidative stress and mitochondrial damage. Three variants of the mortalin gene have been found in Parkinson's patients. Neurons in the Parkinson's brain suffer from both mitochondrial dysfunction and protein accumulation, but the causal relationship is not clear; probing the effects of these gene variants could clarify the pathogenesis of the disease, said Burbulla.

Next up was Geeta Negi, a student at India's National Institute of Pharmaceutical Education and Research in Punjab, whose research concerns the role of the transcription factor NF- $\kappa \mathrm{B}$ in diabetic neuropathy - a crippling complication of diabetes that leads to sensory nerve damage. There are no treatments that block the inflammatory cascade underlying diabetic neuropathy, so interfering with NF- $\kappa B$ could be a promising approach, said Negi.

In the final presentation, Avishek Anant of India's National Institute of Immunology in New Delhi, talked about drug targets in Mycobacterium tuberculosis, the TB pathogen. To better control TB, Anant said, clinicians need many innovations: new drugs to treat multidrug-resistant TB, point-of-care diagnostic tests and a post-exposure vaccine. These needs can seem overwhelming, but Ciechanover reckoned this scope of issues was entirely appropriate for his masterclass: "We are not solving problems here. We are surfacing problems." These three diseases, he said, are a problem now - and epidemics of the future: all are on the rise and none has an obvious cure.

Rather than focus on the specifics of the presentations, Ciechanover prompted a conversation about how best to design selective therapies. Using Negi's NF- $\kappa \mathrm{B}$ idea as an example, Ciechanover identified a difficulty in targeting this protein complex: the promiscuous transcription factor is involved in multiple systems, including neuronal survival, the production of myelin (the protective sheath that encases neurons) and in the expression of genes that block cell death (or apoptosis). "This is one of the most complex transcription factors described," he said. Turning to Negi, he asked: "How would you protect and spare its activity in one cell, and tamper with it in another?"

Ciechanover then turned Negi's problem into a challenge for the audience, asking everyone to imagine themselves in the role of a researcher at a drug company. "I ask you to come up with solutions," he urged, pointing at the audience; hands shot up all around the room. One young cancer researcher suggested attaching a toxin to an antibody that would target a specific antigen in the tissue. "Fantastic," responded Ciechanover. Another proposal: targeting highly activated $\mathrm{NF}-\kappa \mathrm{B}$ with an endogenous regulator that could generally down-regulate background levels of the 
transcription factor. "It lacks specificity," observed Ciechanover. Perhaps, elaborated the student, a vector that directed the regulator to the appropriate tissue, capable of being activated or shut down, would provide the necessary precision.

Ciechanover stalked around the stage, interrupting students to praise or scrutinize each idea in high-energy exchanges that enthralled the room. Students eagerly proffered suggestions, and there were many more raised hands than there was time to hear from each person. Ciechanover steered the discussion beyond the specifics of NF- $\kappa$ B to tackle the broader problem of selective inhibition of biological processes. This is not just a problem of one transcription factor, he said, "this is a problem of medicine." Cancer is the most obvious example: chemotherapy not only kills tumour cells, but does considerable collateral damage to other cells. How can this be avoided?

In the session that followed, Ciechanover offered criticisms and suggestions to hone each participant's idea. One proposal was to deliver, via a viral vector, a protein that inactivates the target. The protein's sequence would be encoded in the vector and controlled by a promoter - a stretch of regulatory DNA - that was tissue-specific, such that the protein would be activated only in the target organs. Ciechanover considered it, pointing out that promoters tend to get shut down by methylation, and therefore cannot act long enough to be effective. Another suggestion was to deliver an agent orally, but turn it into a working drug only at the target site with a technique like photoactivation. Ciechanover embraced an idea to craft a drug that could selectively pass through the relatively leaky vasculature of cancer cells, pointing out that a similar

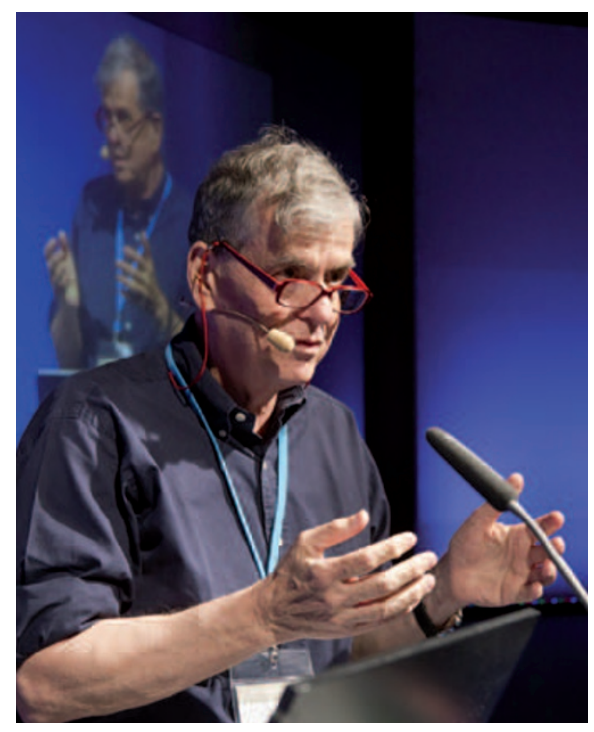

Ciechanover's passion for science is evident.

strategy was used to develop Caelyx/Doxil - a liposome-encapsulated form of the chemotherapeutic agent doxorubicin. Because doxorubicin is highly toxic to the heart, it needs to be wrapped in an artificial liposome to reduce cardiotoxicity.

At each stage of the discussion, Ciechanover pushed the student researchers to think about implementation - to consider potential side effects or other problems that might undermine a promising idea. He pointed out that many strategies have already been worked out for overcoming hurdles in drug development, and suggested that young researchers would be well-advised to keep abreast of the approaches that have succeeded in the past.
The student presenters were energized by the chance to connect intellectually with a Nobel laureate. "It was more than one graduate student can ask for," Anant said afterward. It was an honour, agreed Negi, who said that Ciechanover's enthusiasm and optimism were contagious, spurring her to think more about adapting existing techniques to treat other human diseases. Ciechanover, she said, made the young researchers in the audience "think practically about solutions".

The students were inspired by the fluid, informal conversation. "It was very intense scientifically, and a very sharp discussion," said Gigin Lin of the Institute for Cancer Research in London. Christian Schulz, a PhD student in biochemistry at the University of Göttingen, Germany, agreed, adding that "it's something different for the students to get to speak up more".

In the end, despite the allusion to Renaissance pedagogy, the session did not closely resemble a masterclass where student and teacher engage in a one-on-one instruction. But the principle of an apprentice learning by example rather than through explicit instruction emerged nonetheless. And the arc of the discussion - from the intricacies of the ubiquitin system to the highest hurdles in drug development - provided a worthy intellectual blueprint for a young scientist to follow. Ideally, "the mentor doesn't tell you what the next experiment should be," Ciechanover said. But, by observing how the mentor approaches problems and thinks about solutions, his mindset becomes embedded in your own.

Kat McGowan is a journalist based in New York City.

\section{PRACTICAL ADVICE FROM THE LAUREATES}

\section{Reality of life in the lab}

Just because you've won a Nobel prize doesn't exempt you from the everyday realities of a life in science. In Lindau's Turning the Tables symposium, featuring a panel of Nobel laureates and young researchers, the laureates had an opportunity to query the students about their interests and plans. In the conversations that ensued, some elite names in science provided some down-to-earth advice:

Work hard: In response to a query from Thomas Steitz, who won the Nobel Prize in Chemistry in 2009 , student panellists said they routinely worked long days, but didn't always go to the lab on weekends. Steitz remarked that weekend working was common in his day.

Never eat lunch alone. Steitz lauded the late 1960 s culture of the Laboratory of Molecular Biology in Cambridge, United Kingdom, where meals and tea breaks were always social events, leading to new ideas and collaborations. "Now, people eat their lunch in their office doing email, which I think is a lousy way of doing science."

Speak up. Engage with your advisor - even one with a hands-off management style. "The least successful students and postdocs are the ones who are silent," said Steitz.

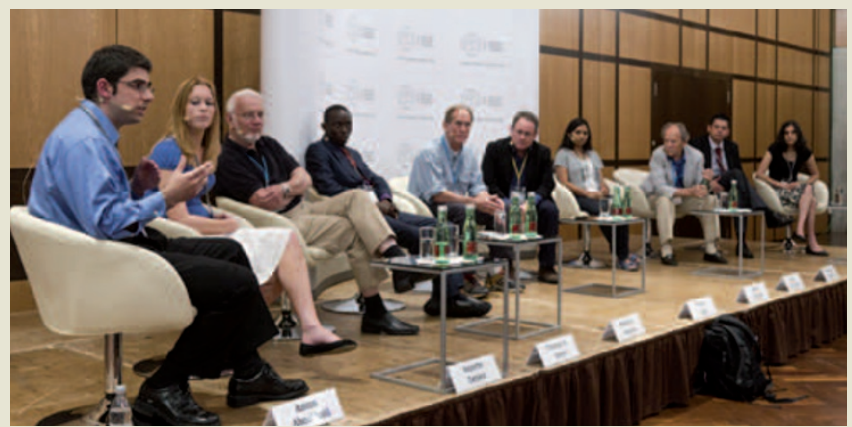

Students and laureates turn the tables on each other.

Creativity is fed by diverse sources. "The best way for the brain to work is to be exposed to different things," said Torsten Wiesel, who shared the 1981 Nobel Prize in Physiology or Medicine. Wiesel cited his life-long interest in art as an inspiration. "I see colleagues who work very hard, doing all the trivial work. Their lives miss some quality of joy." 